\title{
O SENTIDO DA PEDAGOGIA E DO PEDAGOGO NA EDUCAÇÃO ESCOLAR
}

\author{
NEVES, Bruno Miranda ${ }^{1}$ \\ SILVA, Livaldo Teixeira ${ }^{1}$
}

\section{RESUMO}

Por meio de uma abordagem crítica, surge o nosso interesse de ampliar o conhecimento sobre os fundamentos do trabalho do pedagogo, sua importância e especificidade. Parte-se do pressuposto da observação da prática e das pistas conceituais e históricas, numa investigação centrada na práxis educativa e seus condicionantes. Apontamos a Educação como um amplo objeto de estudo, os conceitos, a historicidade e o campo profissional da Pedagogia e do Pedagogo,caracterizando a escola como lócus da formação humana; dessa forma,nos aproximamos do sentido do Pedagogo concreto na Educação Escolar, em especial na Organização do Trabalho Pedagógico.Buscamos essas objetivações partindo de conceitos basilares; para tanto, além da legislação educacional vigente,recorremos a Saviani (1985; 2008; 2012), Libâneo (2008; 2012), Silva (2006) e Franco (2008) como principais referências de estudo.

Palavras-Chave: Pedagogia - Pedagogo - Educação Escolar - Organização do Trabalho Pedagógico.

\begin{abstract}
In the perspective of a critical approach, our interest in expanding knowledge about the labor foundations of pedagogues emerges, taking into consideration its importance and specify. It starts from the assumption of observation of the practice as well as conceptual and historical clues in a research focused on educational praxis and its conditioning. We view Education as a wide object of study, considering its concepts, historicity and the professional field of pedagogy and the pedagogue, featuring school as the locus of human development. In this way we approach the meaning of the concrete Pedagogue in school education, especially in the organization of pedagogical work. We focus on these objectivities starting from basic concepts; Going beyond the current educational legislation, we consider Saviani (1985; 2008; 2012), Libâneo (2008; 2012), Silva (2006) and Franco (2008) as the main study references.
\end{abstract}

KeYWORDS: Pedagogy - Pedagogue - School education - The pedagogical Work Organization.

\footnotetext{
${ }^{1}$ Pedagogo do Instituto de Aplicação Fernando Rodrigues da Silveira (CAp-UERJ).
} 


\section{INTRODUÇÃO}

Foram as inquietações advindas de nossas experiências como docentes e pedagogos em instituições públicas e particulares na Educação Básica e Superior que nos impeliram a estudar a fundamentação do trabalho do pedagogo escolar, assim como sua formação, profissão, identidade e atuação no contexto escolar, ao nos indagarmos sobre a importância e a especificidade de seu papel na escola.

Por entendermos, tal qual Franco (2008, p. 123), que "a essencialidade da identidade do pedagogo deverá ser $a$ investigação educacional, centrada na práxis educativa e seus condicionantes", partimos de nossas práticas escolares e fundamentando-nos nas pistas conceituais e históricas da literatura pedagógica e da análise documental para uma aproximação da realidade concreta do trabalho do pedagogo escolar.

O trabalho foi desenvolvido através de uma revisão de literatura e da legislação específica com caráter qualitativo, procurando identificar nossa problemática nas produções teóricas de autores que se ocupam do estudo do fenômeno educativo, abordando recortes da epistemologia da educação e da Pedagogia, tomadas aqui como pressupostos para a organização do trabalho pedagógico (OTP). Para tanto, empreendemos a análise de leis e documentos oficiais que normatizam a Pedagogia no Brasil (BRASIL, 1996; 2006). Além da legislação educacional vigente, recorremos a Saviani (1985; 2008; 2012), Libâneo (2008; 2012),Silva (2006) e Franco (2008)como principais referências de estudo.

Mas afinal, o que é a Pedagogia e quem é o Pedagogo - artista ou cientista ou técnico? $O$ trabalho do pedagogo se caracteriza pelo seu viés criativo em que a sua capacidade de improviso é preponderante? Trata-se de um trabalho científico, baseado no diálogo com os fundamentos da educação (antropologia, sociologia, história, economia, filosofia, psicologia etc.)? O trabalho pedagógico é definido pela prescrição e execução de rotinas de trabalho? São os pedagogos técnicos da educação?

Por ora, buscamos pontuar sobre as principais objetivações do trabalho do pedagogo nas instituições escolares. Especificamente buscamos conceituar a Educação como objeto de estudo, a Pedagogia e o Pedagogo demonstrando, ainda, que sinteticamente os referenciais teóricos fundamentam sua formação e atuação. Também realizamos uma análise da legislação vigente, especialmente da Lei de Diretrizes e Bases da Educação Nacional (BRASIL, 1996) e das Diretrizes Curriculares para o Curso de Pedagogia, licenciatura (BRASIL, 2006), em seus posicionamentos normativos sobre o campo profissional do Pedagogo (Stricto-Sensu), na tentativa de fomentar uma práxis concreta de sentido e significado para a escola,que na sociedade capitalista é o lócus privilegiado da formação humana.

Não obstante a relevância epistemológica há de se destacar a importância e pertinência do tema neste momento em que tanto a escola quanto os seus profissionais são questionados pelo descumprimento de sua "promessa integradora", vivenciada no cenário no qual direitos sociais duramente conquistados estão sendo demolidos por um conjunto de políticas que visam assegurar a valorização do capital.

\section{A EDUCAÇÃO ENQUANTO OBJETO DE ESTUDO}

Educação compreende o conjunto dos processos, influências, estruturas e ações que intervêm no desenvolvimento humano de indivíduos e grupos na sua relação ativa com o meio natural e social, num determinado contexto de relações entre grupos e classes sociais, visando a formação do ser humano (LIBÂNEO, 2001, p. 160). 
O objeto de estudo da pedagogia é amplo, porém nos deteremos em alguns apontamentos e conceituações basilares.

Para Libâneo (2008), constituem objeto de estudo da Pedagogia tanto os processos formativos quanto à prática educativa, sendo o campo do educativo vasto, porque a educação ocorre em várias instâncias: na família, nos processos de trabalho, nos meios de comunicação, na política etc., e ainda cumpre distinguir diferentes manifestações e modalidades de prática educativa, tais como a educação informal, não-formal e formal.

$\mathrm{Na}$ mesma obra, Libâneo define prática educativa como:

Um fenômeno constante e universal inerente à vida social, se é um âmbito da realidade possível de ser investigado, se é uma atividade humana real, ela se constitui como objeto de conhecimento, pertencendo essa tarefa à pedagogia que é, por isso, teoria e prática da educação (LIBÂNEO, 2008, p. 95-96).

Os estudos de Franco (2008) contribuem para esclarecer aspectos do debate que vem sendo travado na área da educação, a respeito da formação dos docentes; reafirma a tradição teórica em que a pedagogia, como ciência da educação, formula a prática educativa e os elementos científicos e técnicos da formação humana, construindo-se a base de referência para todas as práticas educativas, dentre elas a docência. Daí a necessidade da reflexão sistemática do objeto de estudo.

[...] começarei do incontestável, ao considerar que o objeto de estudo da ciência pedagógica é a educação. Sabe-se da enorme complexidade desse objeto de estudo, e sabe-se também que a educação configura-se, estabelece-se, estrutura-se em diversas dimensões. Sua dimensão privilegiada é a prática educativa, vista como prática social intencionada, na qual confluem as intencionalidades e as expectativas sociais, em que se determinam os contextos da existência humana num determinado grupo social, na qual se concretiza a realidade subjetiva, num processo histórico-social que se renova continuamente. (FRANCO, 2008, p.79-80).

Entendemos que o objeto de estudo da pedagogia seja a educação, reconhecendo as contribuições de outras ciências para a investigação do fenômeno educativo.

Não é nova a questão de se reconhecer a educação como um objeto de estudo bastante complexo. Diferentes filósofos, educadores, professores contataram e discutiram essa especificidade. Mas, apesar desse reconhecimento e dos muitos estudos da área, ainda permanece a questão das possibilidades científicas de uma ciência da educação. (FRANCO, 2008, p. 74).

Neste sentido, Franco (2008, p. 74) nos aponta que "diversas disciplinas têm a educação como seu objeto de estudo e concorda-se que esse objeto, a educação, reveste-se de mil faces para se fazer de inteligível e diversos aportes teóricos, referendam as metodologias para sua compreensão". A autora ainda nos mostra um ponto importante a refletir sobre o objeto de estudo da pedagogia, talvez o principal objetivo que caracterize 0 ato educativo, a formação do homem: "[...] o objeto da pedagogia é o homem em formação, portanto um objeto complexo, que requer do pedagogo uma formação diferenciada, para saber buscar, sem se perder de seu objeto, elementos auxiliares, em ciências afins" (FRANCO, 2008, p. 28).

Parece-nos que esses apontamentos dimensionam a complexidade do campo de estudos da Pedagogia, o que nos faz compreender que mesmo considerando a Pedagogia como Ciência da Edu- 
cação, faz-se necessária à compreensão da totalidade do fenômeno educativo na contribuição de outras ciências que têm a educação como foco de estudo, como por exemplo: a História, a Filosofia, a Sociologia, a Antropologia e a Psicologia. Nesse sentido cabe à pedagogia garantir a compreensão da totalidade dos processos formativos que envolvem o homem em formação, seu objeto de estudo.

A educação "formal" é aquela efetuada por profissionais. Ela se utiliza das ferramentas que postula a pedagogia para atingir objetivos relevantes à prática social. Essa educação é sistematizada, geralmente, de acordo com as áreas do saber humano, corroborando para a assimilação, por parte do educando.Saviani (2008a, p. 9),parafraseando Marx, reafirma que "o capital é a força econômica da sociedade burguesa que tudo domina"e conclui: "podemos dizer que a escola, na sociedade atual, é a força pedagógica que tudo domina". Considerando que é, a partir do mais desenvolvido, que se pode compreender o menos desenvolvido e não o contrário. podemos afirmar que a anatomia da escola é a chave da anatomia da educação.

\section{Pedagogia e Pedagogo: Conceito e HISTORICIDADE}

Neste tópico, explicitaremos conceitos que consideramos fundamentais para a compreensão do sentido da pedagogia e do pedagogo escolar, apresentando formulações históricas e conceituais para melhor perquirirmos ambos.

Buscando abordar questões que envolvem o campo teórico da pedagogia, a sua relação com as demais ciências, a identidade profissional do pedagogo e seu papel diante das realidades contemporâneas, identificamos em Libâneo (2008) as aproximações do conceito de Pedagogia e do fenômeno do qual se ocupa. Para ele, o campo "do conhecimento que se ocupa do estudo sistemático da educação, isto é, do ato educativo, da prática educativa concreta que se realiza na sociedade como um dos ingredientes básicos da configuração da atividade humana" (LIBÂNEO, 2008, p. 29-30).

Em consequência, a Pedagogia é a ciência que investiga práticas, processos, fatos, métodos e formas de educar, sem se restringir a isto, uma vez que ela se constitui em "um campo de conhecimento sobre a problemática na sua totalidade e historicidade, e, ao mesmo tempo, uma diretriz orientadora da ação educativa" (LIBÂNEO, 2008, p.29-30).

Por sua vez, Franco (2008, p.113) define a pedagogia como "uma ciência que tem por fim específico o estudo e a compreensão da práxis educativa, com vistas à organização de meios e processos educativos de uma sociedade"; e, em seus estudos das obras clássicas da pedagogia, ela percebe claramente que, para além de ciências, há uma tendência a também considerá-la como arte. Assim, muitas vezes a pedagogia é conceituada como a ciência e a arte da educação ou mesmo a ciência da arte educativa.

A historicidade da investigação de uma ciência pedagógica é necessária. Saviani (2008a, p. 01-02) faz alguns apontamentos sobre a Pedagogia em sua historicidade, revelando que se desenvolveu em íntima relação com a prática educativa, constituindo-se como a teoria ou ciência dessa prática, tendo sido identificada em determinados contextos com o próprio modo intencional de realizar a educação. Por isto, entende que se construiu uma rica tradição teórica e científica sobre a prática educativa que deve continuar a ser desenvolvida, até mesmo por causa das inúmeras negativas de que foi alvo na história do pensamento humano.

Saviani (2008) nos mostra ainda que ao longo da história a pedagogia foi se constituindo em caminhos recíprocos 
aos da educação. E ainda continua sua explanação, asseverando:

[que] a Pedagogia foi firmando-se como correlato a educação, entendida como o modo de apreender ou de instituir o processo educativo. Efetivamente, a educação aparece como uma realidade irredutível nas sociedades humanas. Sua origem confunde-se com as origens do próprio homem. $\mathrm{Na}$ medida em que o homem se empenha em compreendê-la e busca nela de maneira intencional, vai constituindo um saber específico que, desde a Paidéia grega, passando por Roma e pela Idade Média, chega aos tempos modernos fortemente associados ao termo "pedagogia". (SAVIANI, 2008, p.1-2)

Saviani (1985, p. 27-28) ainda esclarece que a palavra pedagogia "traz sempre ressonâncias metodológicas, isto é, de caminho através do qual se chega a determinado lugar. Aliás, isto já está presente na etimologia da palavra: conduzir (por um caminho) até determinado lugar".

A partir dessas definições, podemos afirmar que a pedagogia é um campo do conhecimento que se preocupa com a educação, e com isso o pedagogo seria aquele que se dedicaria às questões ligadas ao processo educacional.

Após termos definidos o termo pedagogia, percebemos como ainda mais complexa a questão da identidade, nos impelindo a refletir: Quem é o Pedagogo? "Essa pergunta pode ter uma resposta direta, imediata e simples: Ora! Pedagogo é quem se formou em pedagogia e, consequentemente, atua no campo da educação" (SAVIANI, 2012, p. 4). De sua parte, Libâneo (2008), considera o conceito de pedagogo (Stricto-sensul) sintetiza uma visão da administração escolar que tem como seu objeto de estudo a organização.

[...] o pedagogo é o profissional que atua em várias instâncias da prática educativa, direta ou indiretamente ligadas à organização e aos processos de transmissão e assimilação de saberes e modos de ação, tendo em vista objetivos de formação humana previamente definidos em sua contextualização histórica (LIBÂNEO, 2008, p.33).

Já Franco (2008) coloca a pesquisa como princípio pedagógico organizacional da formação, colocando o projeto político e a visão emancipadora da educação nos objetivos da ação daquele profissional. Segundo a autora,"o pedagogo será aquele profissional capaz de mediar teoria pedagógica e práxis educativa e deverá estar comprometido com a construção de um projeto político voltado à emancipação dos sujeitos da práxis na busca de novas e significativas relações sociais desejadas pelos sujeitos" (FRANCO, 2008, p.110).

Saviani (1985), ao proferir discurso de paraninfo de uma Turma de Licenciatura em Pedagogia, fez uma analogia do pedagogo contemporâneo com a origem etimológica do termo, ou seja, de guia criança para a "condução à cultura" e posiciona sua pedagogia contrariando o "relativismo pedagógico" sinalizando um pedagogo situado na perspectiva de "uma pedagogia afirmativa do ato de ensinar" (DUARTE, 1998). Daí o domínio sistemático e intencional das "formas de organização do processo de formação cultural que se dá no interior das escolas" engendra a necessidade de um "espaço organizado de forma sistemática com o objetivo de possibilitar o acesso à cultura erudita" (SAVIANI, 1985 p. 28). Para ele, o pedagogo "é aquele que possibilita o acesso à cultura, organizando o processo de formação cultural. É, pois, aquele que domina as formas, os procedimentos, os métodos através dos quais se chega ao domínio do patrimônio cultural acumulado pela humanidade" (SAVIANI, 1985 p.27-28).

Os conceitos apresentados podem no indicar qual é o campo profissional do Pedagogo escolar em que poderíamos 
afirmar que o foco central desse profissional é a OTP, em uma dimensão em que não pode ser confundido com a didática. Nesse sentido, nos aponta para um generalista, com bases no conhecimento filosófico e científico, especificamente da Organização do Trabalho Pedagógico; o que, em nossa compreensão, pode nos indicar uma função direta e indireta de suporte a docência, no caso da instituição escolar.

\section{O campo profissional do Pedagogo ESCOLAR E A LEGISLAÇÃO VIGENTE}

Não faremos aqui um resgate histórico do Curso de Pedagogia no Brasil. porém, faz-se necessário localizar o recorte temporal o qual identificamos a partir da Lei de Diretrizes e Bases da Educação Nacional em vigor, para ressaltarmos que as regulamentações retomam o desenvolvimento do curso de pedagogia no Brasil, demonstrando que a história do curso é a história da questão de sua identidade. 0 curso de Pedagogia, desde a sua fundação em 1939, na Universidade do Brasil no Rio de Janeiro, sofre uma crise de identidade entre a formação docente e a técnica, complicando ainda mais a definição do campo de estudos e por consequência o campo de atuação (SILVA, 2006).

A Resolução do CNE/CP No 1, de 15 de maio de 2006, institui as Diretrizes Curriculares Nacionais para o Curso de Graduação em Pedagogia, licenciatura (BRASIL, 2006). Essa diretriz fundamentou-se na docência como prioridade na formação do Licenciado em Pedagogia. Dessa forma, também podemos deduzir que se o curso de Pedagogia é uma licenciatura, isso pressupõe a possibilidade de existência de um bacharelado, o que pode fundamentar o resgate das investigações do campo pedagógico, já que a forma de organização nas diretrizes não prioriza a formação do pedagogo stricto sensu (LIBÂNEO, 2008).
Art. 20: As Diretrizes Curriculares para o curso de Pedagogia aplicam-se à formação inicial para o exercício da docência na Educação Infantil e nos anos iniciais do Ensino Fundamental, nos cursos de Ensino Médio, na modalidade Normal, e em cursos de Educação Profissional na área de serviços e apoio escolar, bem como em outras áreas nas quais sejam previstos conhecimentos pedagógicos (BRASIL, 2012).

O Conselho Nacional de Educação, em 13/12/2005, aprovou o Parecer CNE/CP No 5/2005 que trata das Diretrizes Curriculares Nacionais para o Curso de Pedagogia e este foi reexaminado pelo Parecer CNE/CP no 3/2006, aprovado em 21/2/2006, e esclarece que "a Comissão Bicameral de Formação de Professores revisou minuciosamente o texto do Projeto de Resolução contido no Parecer CNE/CP no 5/2005 e as disposições legais vigentes e resolveu propor a seguinte emenda retificativa ao art. 14 da Resolução CNE/CP No 01 de 2006:

Art. 14. A Licenciatura em Pedagogia nos termos do Parecer CNE/CP no 5/2005 e desta Resolução assegura a formação de profissionais da educação prevista no art. 64, em conformidade com o inciso VIII do art. $3^{\circ}$ da Lei $n^{\circ}$ 9.394/96.

$\S 1^{\circ}$.Esta formação profissional também poderá ser realizada em cursos de pósgraduação, especialmente estruturados para este fim e abertos a todos os licenciados.

$\S 2^{\circ}$. Os cursos de pós-graduação indicados no $\S 1^{\circ}$ deste artigo poderão ser complementarmente disciplinados pelos respectivos sistemas de ensino, nos termos do Parágrafo único do art. 67 da Lei no 9.394/96. 
Consideramos que a preocupação com a docência foi de fundamental importância para valorização do campo profissional do pedagogo, considerando a docência como atividade principal do campo educativo. Porém, os cursos de formação de profissionais da educação ficam alijados da formação pedagógica ampla, que só pode ser concretizada por uma ciência que tem como seu objeto de estudo o fenômeno educativo na sua totalidade.

Apesar de outras ciências investigarem a educação, isso se dá de forma fragmentada, cabendo indagar, por meio de uma investigação sócio-histórica, as possibilidades da Pedagogia enquanto ciência da educação, orientadora da prática educativa. Em nossa investigação, interpretamos os conceitos de pedagogo e pedagogia para além da docência. Posto que, a docência é a atividade peculiar da pedagogia, porém não constitui por si só a totalidade do conhecimento pedagógico, ou seja, todo o pedagogo é um professor, mas nem todo o professor é um pedagogo. A esta noção, Libâneo (2008) dá o nome de Pedagogo "Stricto Sensu".

\section{A Organização do trabalHo Pedagógico e a Orientação EDUCACIONAL NA ESCOLA}

Na sociedade capitalista a escola é a instituição privilegiada para a transmissão-assimilação do saber sistematizado, local próprio de atuação do profissional da educação. Portanto, uma escola real precisa organizar suas práticas de modo intencional, uma forma que venha prefigurar a superação histórica do modo de produção vigente, sendo o espaço vinculado ao interesse do social e não do capital.

Considerando que o objeto de estudo da Pedagogia sejam os processos educativos e que é uma ciência da práxis que deve centrar nos aspectos éticopolíticos do homem em formação, os pedagogos escolares (não docentes) têm como principal atribuição a OTP e por decorrência a orientação educacional e pedagógica unitária.

Libâneo (2012, p. 481) sugere que essas práticas podem ser articuladas em seis áreas de atuação da gestão da escola:

a) o planejamento e o projeto pedagógico-curricular; b) a organização e o desenvolvimento do currículo; c) a organização e o desenvolvimento do ensino; d) as práticas de gestão técnicoadministrativas e pedagógico-

curriculares; e) o desenvolvimento profissional; f) a avaliação institucional e da aprendizagem.

Conforme o autor,

Essas áreas de atuação estão articuladas entre si, formando três blocos: o primeiro, de áreas vinculadas às finalidades da escola (projeto, currículo, ensino); o segundo, daquelas relacionadas ao meio (práticas de gestão e desenvolvimento profissional; o último, o da avaliação, envolvendo todas as demais áreas, incluindo os objetivos e resultados. (LIBÂNEO, 2012, p. 481-482)

Buscamos interpretar essas áreas organizacionais da prática numa tentativa de colocar uma sintonia com os modos de ação do pedagogo nas instituições escolares:

1- O Planejamento e o Projeto pedagógico-curricular: (Objetivos e finalidades da Escola) e Plano de Trabalho Docente (sala de aula). Esses eixos, considerando nossa perspectiva, centrados nos saberes clássicos, nos conhecimentos científicos, artísticos e filosóficos em suas formas mais desenvolvidas de transmissãoassimilação, sendo esse, um instrumento de ação-reflexão-ação de modo a organizar intencionalmente a prática educativa coletivamente. Sugerimos o movimento 
metodológico da pedagogia histórico-crítica, tendo com precursor Dermeval Saviani, que propõe cinco momentos a serem articulados: 1- Prática Social Inicial do Conteúdo, 2- Problematização, 3Instrumentalização, 4- Catarse, 5Prática Social Finali (SAVIANI, 2008b);

2- Avaliação: Tomada como ponto de partida para toda a OTP;

3- Conselho de Classe: Fundamentado nos resultados avaliativos, centrando-se objetivamente na busca de elementos que promovam a aprendizagem do aluno concreto em suas condições sócio-históricas;

4- Formação Continuada: Levando em conta currículo escolar, em seus elementos: as metodologias, os conteúdos de ensino e a avaliação; ou seja, por meio das formas mais desenvolvidas, sendo fundamentada para uma formação ético-política, compromissada com a socialização do patrimônio cultural da humanidade;

5- Relação Escola-Comunidade:A Orientação Educacional visando à inclusão do aluno, seu processo de autoconhecimento e escolhas conscientes, fundamentando-se no estudo dos desafios educacionais contemporâneos e nas bases psicopedagógicas voltadas para a socialização e a aprendizagem.

Após colocarmos, de forma intencional, os conteúdos da ação, propomos também uma integração com os modos do fazer pedagógico escolar, a transmissão-assimilação dos conteúdos clássicos e as formas mais desenvolvidas da educação escolar, de modo que cada conteúdo da ação gere demandas que são oriundas da necessidade da prática educativa. Sendo assim, os sentidos da pedagogia e do pedagogo emanam da prática social que se pretende numa perspectiva educacional transformadora das condições de não aprendizagem para a condição de aprendizagem.

\section{CONSIDERAÇÕES FINAIS}

O pedagogo é o mediador dessas condições e por isso exige e reclama por respeito à natureza do seu trabalho e às especificidades de suas funções na instituição escolar. Nessa busca identificamos, de fato, o sentido do Pedagogo concreto, apontando suas principais demandas para as instituições escolares, numa prática fundamentada, sistematizando suas funções,onde os conceitos possam contribuir para que a escola tenha amparo teóricoprático para cumprir sua histórica função social.

Ao conceituar Pedagogia e Pedagogo, caracterizar o curso de Pedagogia no Brasil em um recorte dos aspectos históricos que desembocaram nos dias atuais, por meio da análise documental e dos referenciais teóricos, foi possível fundamentar a atuação por meio da conceituação de uma prática concreta centrada na historicidade da escola como lócus da formação humana.

Embora as Diretrizes Curriculares do Curso não privilegiem a formação do pedagogo (stricto sensu) como centralidade no seu objeto de estudo, o próprio documento diretamente abre esse espaço pra essa formação evocando o artigo 64 da LDBEN 9.394/96. Isso nos sugere a importância tanto do profissional para a sociedade quanto para a ampliação dos estudos em torno da formação do pedagogo escolar.

A atividade do pedagogo se trata de um trabalho científico, baseado no diálogo com os fundamentos da educação (antropologia, sociologia, história, filosofia, psicologia, etc.); porém, não é dispensável uma ciência que tome a Educação na totalidade como objeto de estudo, sendo o fenômeno e a prática educativa sintonizados na compreensão do homem em for- 
mação. Também podemos afirmar que o trabalho pedagógico se caracteriza pelo seu viés criativo em que a sua capacidade de improviso é preponderante, tendo aí uma dimensão artística.

A pedagogia, por pertencer às ciências humanas, não centra seus esforços epistemológicos na tecnologia. Suas técnicas são, antes de tudo, para a formação humana, portanto, nunca separada da relação humana. O trabalho pedagógico é definido pela prescrição e execução de rotinas de trabalho; para qualificar o processo educativo, os profissionais "não docentes" precisam forjar um elo entre a teoria e a prática, precisam também articular o pedagógico e o administrativo, de maneira indissociável, e isso exige uma sistematização bastante precisa das práticas de organização do processo pedagógico. Então podemos afirmar que os pedagogos também são técnicos da educação.

E, por fim, colocamos nesse cenário de sentidos do educador profissional, o pedagogo, a escola como lócus privilegiado da formação humana na sociedade, e por consequência, a Organização do Trabalho Pedagógico Escolar e a Orientação Educacional. Esperamos que nossos breves apontamentos possam contribuir para a compreensão do trabalho pedagógico escolar à luz de princípios éticos, políticos e sociais, a fim de lograr e produzir orgânicas similaridades com as contradições e desafios de nosso tempo e a tarefa histórica de formar educadores profissionais que repercutam na qualidade da Educação Básica.

\section{REFERÊNCIAS BIBLIOGRÁFICAS}

BRASIL. Lei $n^{\circ}$ 9.394, de 20 de dezembro de 1996. Estabelece as diretrizes e bases da educação nacional. Brasília: Ministério da Educação e do Desporto, 1996.

- Conselho Nacional de Educação.Diretrizes Curriculares Nacionais para o Curso de Pedagogia. Parecer
CNE/CP.n05, de 13 de dezembro de 2005. Disponível em <http://portal.mec.gov.br/cne/arquivos/pd f/rcp01_06.pdf >. Acesso em 01 nov 2014.

DUARTE, Newton. Concepções Afirmativas e Negativas Sobre o Ato de Ensinar. Cadernos CEDES,Campinas, v. 19, n. 44, p. 85-106, 1998.

FRANCO, Maria Amélia do Rosário Santoro. Pedagogia como ciências da educação. São Paulo: Cortez, 2008.

GASPARIN, J. L. Uma didática para a Pedagogia histórico-crítica. Campinas, SP: Contemporânea, 2002.

LIBÂNEO, José Carlos. Pedagogia e pedagogos, para quê? São Paulo, Cortez, 2008.

Educação escolar: políticas, estruturas e organização. São Paulo: Cortez, 2012.

Pedagogia e pedagogos: inquietações e buscas. Educar, Curitiba, n. 17, p. 153-176, 2001.

PARANÁ. Secretaria de Estado da Educação. Superintendência da Educação. Coordenação de Gestão Escolar. Organização do trabalho pedagógico / Secretaria de Estado da Educação. Curitiba: SEED - PR, 2010.

PARO, Vitor Henrique. Administração escolar: introdução crítica. São Paulo, Cortez, 2006. SAVIANI, Dermeval. Sentido da Pedagogia e papel do pedagogo. Revista da Ande, São Paulo, n. 9, 1985.

A pedagogia no Brasil: história e teoria. Campinas,SP: Autores Associados, 2008a.

Escola e Democracia. Campinas, SP: Autores Associados, 2008b. 
.Pedagogia histórico-crítica: primeiras aproximações. Campinas, SP: Autores Associados, 2011.

O papel do Pedagogo como articulador do trabalho pedagógico na sociedade do capital. [Palestra UENP Cornélio Procópio, em 8 de março de 2012]. Disponível em: $<$ http://gephisnop.weebly.com/uploads/2/ 3/9/6/23969914/o_papel_do_pedagogo_c o-

mo_articulador_do_trabalho_pedagogico_ na_sociedade_do_capital.pdf $>$. Acesso em 01 nov 2014.

SILVA, Carmem Silvia Bissolli da. Curso de pedagogia no Brasil: historia e identidade. 3 ed. Campinas, SP: Autores Associados, 2006.

Recebido em: 29/05/2015

Aceito em: 24/05/2015

' $O$ pedagogo formado em Pedagogia, que se preocupa em investigar o fenômeno educativo em sua totalidade. No caso escolar, esse educador exerce funções relativas ao trabalho pedagógico amplo e não especificamente a docência.

ii Esses movimentos foram estudados por Gasparin (2002) e publicados na obra "Uma didática para a pedagogia histórico-crítica", na qual esses passos/momentos são minuciosamente explicitados. 